\title{
Rectal Carcinoma Metastasis to Oral Cavity : A Rare Presentation
}

\author{
Ashwini Dhananjay Mane-Patil and Prashant Shivaji Mane* \\ Dept. of Pathology, Kolhapur Cancer Centre, Kolhapur, Maharashtra, India
}

\section{ABSTRACT}

Colorectal cancer is $3 \mathrm{rd}$ most common cancer all over the world. Metastasis in colorectal cancer is common and seen in approximately $30 \%$ cases. Metastatic pattern in colorectal cancer depends upon the primary tumour site and histological subtypes. Liver is the most common site for metastasis. Oral cavity is very rare site for metastasis. Here, we report a case of 52 year old male, diagnosed with rectal adenocarcinoma with liver and lung metastases and presenting with oral ulcer. Histopathological examination of oral ulcer revealed metastatic adenocarcinoma. We are presenting it as a rare case report and reviewing similar published cases.

Keywords: Oral Ulcer, Colorectal Cancer, Metastasis

\section{Introduction}

Worldwide, colorectal cancers (CRC) are $3^{\text {rd }}$ most common cancer. ${ }^{1}$ Metastasis is common in CRC and indicates grim prognosis with low survival rates. CRC most commonly metastasize to the liver, lung and peritoneum but may also spread to lymph nodes, bone and other sites. ${ }^{1,2} \mathrm{CRC}$ metastasis to soft tissue is very rare presentation.

Metastasis to oral cavity from any primary tumour in the body is rare, comprising less than $1 \%$ of oral cavity tumours. ${ }^{3,4}$ Most common source are tumours of lung, breast and kidney., ${ }^{3,4}$ The jawbones are twice as common for metastasis than the oral mucosa. ${ }^{3,4}$

Thus, metastasis to oral cavity soft tissue is rare presentation and even rarer is the CRC metastasis to oral cavity. Here we present one such case with rectal adenocarcinoma metastasis to gingiva.

\section{Case}

A 52 year old male patient presented with altered bowel symptoms and mucus in stool, since 1 month, in May 2017. He also complained of decreased appetite and weight loss. His general condition was good and per rectal examination showed a proliferative growth in rectum, $2 \mathrm{~cm}$ from anal verge. Computed Tomography (CT) abdomen and pelvis reported rectal carcinoma with liver metastases and metastatic lymphadenopathy involving perirectal, retroperitoneal, pre-aortic and para-aortic lymph nodes. Rectal biopsy was reported as adenocarcinoma. He was immediately started on chemotherapy FOLFOX-4 (Oxaliplatin + Folinic Acid + 5-Fluorouracil). In August 2017, after completing six cycles of FOLFOX-4, he complained of cough. CT scan was advised for reassessment and revealed progression of disease with new lung metastases. Patient clinical condition and prognosis was explained to the relatives and chemotherapy regimen was changed to FOLFIRI (Irinotecan + Folinic Acid + 5-Fluorouracil). CT scan after six cycles of FOLFIRI revealed partial response to chemotherapy, so six more cycles of FOLFIRI were advised. His carcino-embryonic antigen (CEA) level was 10.96ng/ml. But, patient defaulted and came after 4 months in March 2018 with complaints of constipation and difficulty in passing urine. CT scan findings were suggestive of progression of disease and his CEA level rose to $362.75 \mathrm{ng} / \mathrm{ml}$. Chemotherapy was resumed with FOLFIRI. Six cycles of FOLFIRI were completed. He visited in June 2018 with lower abdomen pain and distension. Ascitic tapping was done. He also showed $1 \mathrm{x} 1 \mathrm{~cm}$ oral ulcer at right upper alveolus near last molar. Oral ulcer biopsy was taken and was reported as metastatic adenocarcinoma (Fig 1). Immunohistochemistry was positive for CK20, CDX2 and negative for CK7 (Fig 2). CT scan revealed progression of diseases. In July 2018 , patient succumbed to the disease and died at home.

\section{Discussion}

Metastases are common in CRC. Riihimaki et al studied 49096 CRC cases, and found metastases in $30.48 \%$ cases. ${ }^{1}$ Similarly, Hugen et al reported metastases in $28.9 \%$ cases. $^{2}$ Metastasis in CRC can be synchronous or metachronous. Metastatic pattern in CRC varies with the primary tumour site and histological subtypes. ${ }^{1,2}$ The frequency of liver metastases does not differ between colon and rectal cancer patients. However, in comparison, colon cancer metastasizes more frequently to intra-abdominal sites and rectal cancer metastasizes more frequently to extra- 
Table 1: Reported cases of colorectal carcinoma metastasis to oral cavity.

\begin{tabular}{|c|c|c|c|c|c|c|c|c|c|}
\hline Author & $\begin{array}{l}\text { Age in } \\
\text { yrs }\end{array}$ & Sex & $\begin{array}{l}\text { Primary } \\
\text { tumour }\end{array}$ & $\begin{array}{l}\text { Interval } \\
\text { between } \\
\text { primary and } \\
\text { oral lesion }\end{array}$ & $\begin{array}{l}\text { Syl } \\
\text { Me }\end{array}$ & Lesion & Site & Other metastasis & $\begin{array}{l}\text { Death after } \\
\text { oral lesion }\end{array}$ \\
\hline Lagha A et al ${ }^{5}$ & 46 & M & ACR & $12 \mathrm{mths}$ & $\mathrm{Me}$ & Mass & Gingiva & Liver, lung & 4 mths \\
\hline Usman $\mathrm{N}$ et $\mathrm{al}^{6}$ & 60 & M & ACR & $24 \mathrm{mths}$ & $\mathrm{Me}$ & Mass & $\begin{array}{l}\text { Buccal } \\
\text { mucosa, GB } \\
\text { sulcus, gingiva }\end{array}$ & $\begin{array}{l}\text { LN, bone, adrenals, } \\
\text { spinal cord }\end{array}$ & 4-6 mths \\
\hline Almangush $\mathrm{A}$ et $\mathrm{al}^{7}$ & 61 & $F$ & ACR & $15 \mathrm{mths}$ & $\mathrm{Me}$ & Mass & GB sulcus & Liver, spine, skin & $3 \mathrm{mths}$ \\
\hline Gill KS et al ${ }^{8}$ & 57 & M & ACR & $24 \mathrm{mths}$ & $\mathrm{Me}$ & Mass & Tongue & LN, lung & NK \\
\hline Singh $\mathrm{T}$ et $\mathrm{al}^{9}$ & 42 & $F$ & ACR & $38 \mathrm{mths}$ & $\mathrm{Me}$ & Mass & Floor & Recurrence & 20 days \\
\hline Pelissari C et al ${ }^{10}$ & 64 & $F$ & ACC & $36 \mathrm{mths}$ & Me & Mass & Gingiva & No mets & 6 mths \\
\hline Bhaskaran A et al ${ }^{11}$ & 92 & M & ACRS & NA & Sy & Ulcer & Tongue & $\begin{array}{l}\text { LN, liver, lung, brain, } \\
\text { bone, retroperitoneum }\end{array}$ & NK \\
\hline Yamauchi $\mathrm{M}$ et al ${ }^{12}$ & 50 & M & ACR & NA & Sy & Ulcer & Gingiva & Lung, liver, spleen & NK \\
\hline Baranović $\mathrm{M}$ et $\mathrm{al}^{13}$ & 78 & M & ACR & $18 \mathrm{mths}$ & $\mathrm{Me}$ & Mass & Gingiva & Liver & 4 mths \\
\hline Watanabe $\mathrm{M}$ et al ${ }^{14}$ & 64 & M & ACR & $84 \mathrm{mths}$ & Me & Mass & Gingiva & Lung, vertebral body & 2 mths \\
\hline Ren QG et al ${ }^{15}$ & 60 & M & ACC & $24 \mathrm{mths}$ & Me & Mass & Gingiva & Liver & NK \\
\hline Present case & 52 & M & ACR & $14 \mathrm{mths}$ & $\mathrm{Me}$ & Ulcer & Gingiva & LN, liver, lung, & $1 \mathrm{mth}$ \\
\hline
\end{tabular}

M: Male; F: Female; ACR: Adenocarcinoma rectum; ACC: Adenocarcinoma colon; ACRS: Adenocarcinoma rectosigmoid; Sy: Synchronus; Me: Metachronus; NA: Not applicable; NK: Not known; GB: Gingivo-buccal; LN: Lymph node

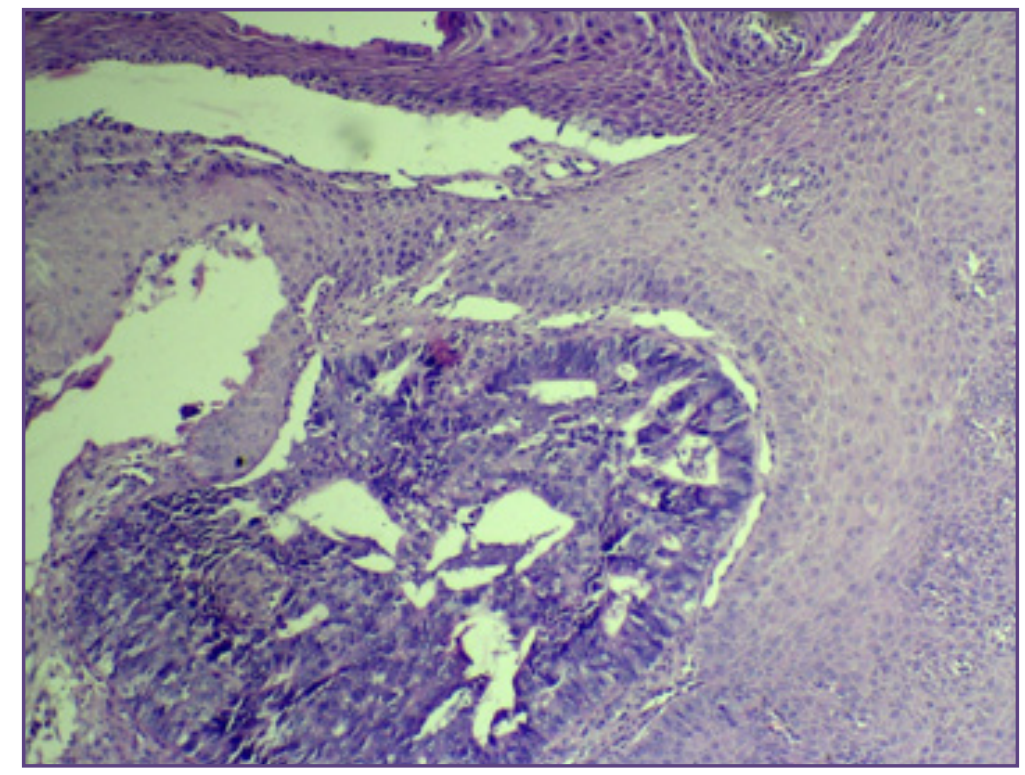

Fig. 1: Metastatic deposits of adenocarcinoma rectum in alveolar mucosa (H\&E 40X). 


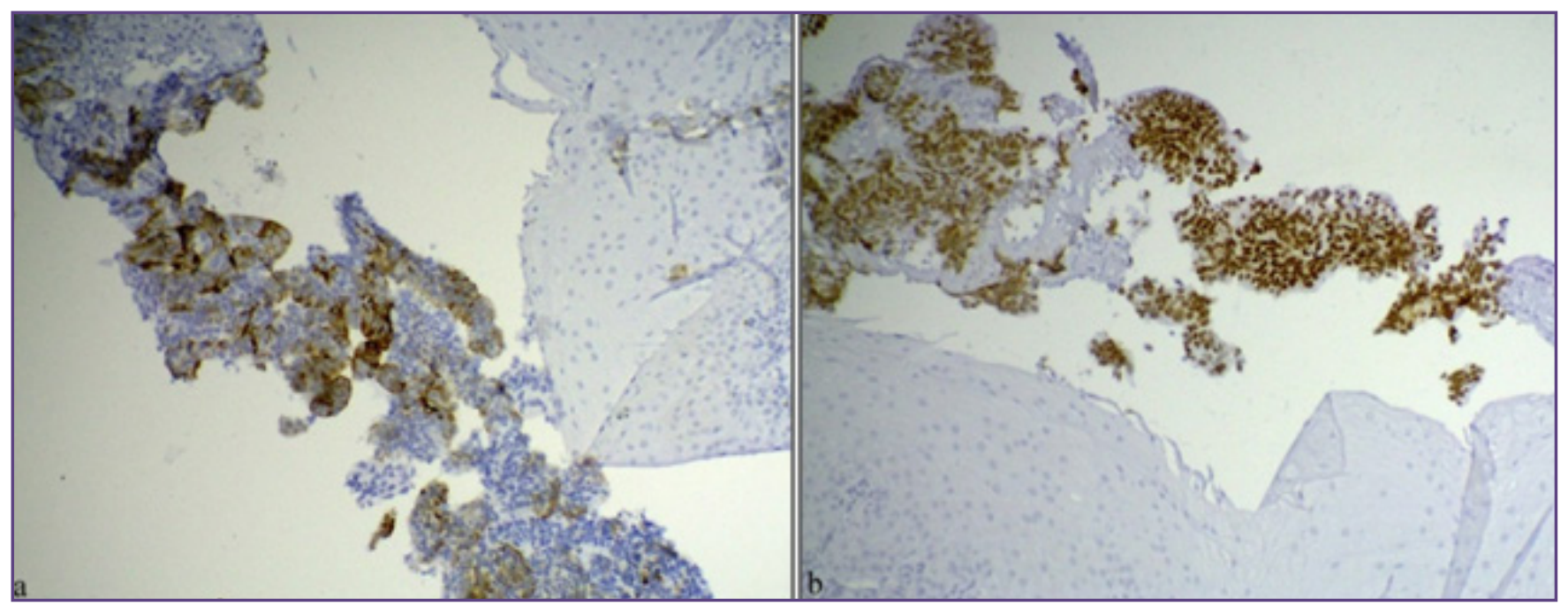

Fig. 2: Immunohistochemistry positive for a) CK20, b) CDX2.

abdominal sites. The higher rate of distant metastases in rectal cancer can be explained by the venous drainage of the rectum bypassing the liver and draining into the inferior vena cava. ${ }^{1,2}$ Adenocarcinoma more frequently metastasizes to the liver, while mucinous and signet ring cell carcinoma metastases more frequently to peritoneal surface.

The oral cavity is uncommon site for metastatic deposit for any primary tumour in the body. Metastasis to oral cavity is usually a late complication and indicates widely disseminated disease with poor prognosis. Lung is the most common primary in males and breast is most common primary in females for oral cavity metastasis. ${ }^{3,4}$ CRC metastasis to oral cavity is rare and when present, it is usually associated with multiple site metastases and thus carry unfavourable prognosis. Oral cavity metastasis may involve jaw bone or soft tissue. Metastasis is more common in jaw bone than oral cavity soft tissue. In the oral soft tissue, gingiva is the most common site because of its rich blood supply and chronically inflamed nature. ${ }^{3,4}$ It presents as ulcerated lesion or exophytic growth. Tongue is the second common site. Patients usually present with pain, bleeding, dysphagia and disfigurement. Possible mechanism for oral metastasis can be attributed to Batson's venous plexus extending from the skull to the sacrum. This valve less system theoretically offers less resistance to the spread of tumour emboli. ${ }^{3,4}$

With known history of primary tumour elsewhere, diagnosis becomes easy with histopathology for metastasis in oral cavity. But, in cases of occult primary, oral lesion could be the only complaint. In such cases immunohistochemistry is useful in making the diagnosis. CRC are positive for CK20, CDX2 and negative for CK7 on immunohistochemistry.
Chemotherapy is the treatment of choice for metastatic CRC. Surgical treatment is planned for patients with limited involvement of distant organs particularly, liver and lung. Mean survival time after diagnosis of metastasis in oral cavity is 6-8 months. ${ }^{5-8}$

As the CRC metastasis to oral cavity soft tissue is rare presentation, there are very few published case reports. We found 11 such published cases with Google search engine. A brief review of 11 published cases and the present case is given in Table 1.

It is observed that, sixth and seventh decade is the most common age group affected. Men are more commonly affected than women. Rectum is the most common primary site. The minimum time interval between primary tumour and development of oral lesion is 1 year and maximum time interval is 7 years. Gingiva is the most common site for metastasis. Oral lesion mostly present as a growth and sometimes with ulcerated lesion. Metastases to oral cavity usually appear after the primary tumour. But in two cases, oral ulcer was the initial clinical presentation, which led to the diagnosis of primary tumour. Most of the cases show at least one other metastatic site along with oral metastases. Singh et al reported a case with no other metastases but with history of recurrence at presacral region. ${ }^{9}$ Pelissari et al reported a rare case with no history of recurrence or other site metastases. ${ }^{10}$ Ten patients died within six months of development of oral metastasis.

\section{Conclusion}

Colorectal carcinoma metastases to oral cavity soft tissue are rare presentation. Rectal adenocarcinoma show more tendencies to spread to oral cavity soft tissue than colon cancer. These lesions usually present as gingival growth, 
but can present with an ulcerative lesion. These are usually accompanied with multiple site metastases, thus carrying poor prognosis with less than six months survival. So, metastasis should be considered in differential diagnosis for oral ulcer, particularly in patients with known primary elsewhere.

\section{References}

1. Riihimaki M, Hemminki A, Sandquist J, Hemminki K. Patterns of metastasis in colon and rectal cancer. Sci Rep [Internet]. Nature Publishing Group; 2016;1-9. Available from: http://dx.doi.org/10.1038/srep29765

2. Hugen N, Velde CJH, Wilt JHW, Nagtegaal ID. Metastatic pattern in colorectal cancer is strongly influenced by histological subtype. Annals of Oncology 2014 Feb 6;25:651-657.

3. Rao RS, Patil S, Sanketh DS, Amrutha N. Metastatic tumors of the oral cavity. J Contemp Dent Pract 2014;15(2):263-271.

4. Rao RS, Patil S, Sanketh DS, Amrutha N. Metastatic tumors of the oral cavity. J Contemp Dent Pract 2014;15(2):263-271.

5. Lagha A, Chraiet N, Krimi S, Ayadi M, Rifi H, Raies $\mathrm{H}$ et al. Gingival metastasis from rectal cancer. IJCRI 2012;3(1):24-26.

6. Usman N, Kattepur A, Gopinath KS. Metachronous metastasis to the oral cavity from carcinoma rectum - a case report and review of literature. Indian J Surg Oncol 2014 Dec;5(4):303-306.

7. Almangush A, Asikainen A, Ristimäki A, Haglund C, Hagström J. Oral metastasis from rectal adenocarcinoma: case report. Case Reports in Clinical Pathology 2014;1(2):63-66.

8. Gill KS, Frattali MA. Colorectal Adenocarcinoma Metastasis to the Tongue. Case Reports in Otolaryngology 2015;1-5.

9. Singh T, Usha A, Satheesh CT, Lakshmaiah KC, Suresh TM, Govindbabu K et al. Floor-of-mouth metastasis in colorectal cancer. Ann Saudi Med 2011; 31(1):87-89.

10. Pelissari C, Cavalcanti D, Braz-Silva PH, Gallottini M, Trierveiler M. Metastatic colorectal adenocarcinoma in oral cavity: case report and literature review. J. Oral Diag. 2018;03:e20180014.

11. Bhaskaran A, Harding S, Courtney D. An unusual presentation of metastatic colon adenocarcinoma in the oral cavity. Case Reports in Dentistry 2011;1-2.

12. Yamauchi M, Shinozakia K, Doia M, Nittaa T, Nishisakab $\mathrm{T}$. A case of gingival metastasis from rectal cancer in which immunohistochemistry and PET-CT were useful for the diagnostic procedure. Case Rep Oncol 2014;7:246-251.

13. Baranović M, Vidaković B, Sauerborn D, Perić B, Uljanić I, Mahovne I. Colorectal adenocarcinoma metastasizing to the oral mucosa of the upper jaw. Srp Arh Celok Lek 2015 May-Jun;143(5-6):314-316.

14. Watanabe M, Tada M, Satomi T, Chikazu D, Mizumoto M, Sakurai H. Metastatic rectal adenocarcinoma in the mandibular gingiva: a case report. World Journal of Surgical Oncology 2016;14(199):1-5.

15. Ren QG, Huang T, Yang SL, HU JL. Colon cancer metastasis to the mandibular gingiva with partial occult squamous differentiation: a case report and literature review. Molecular And Clinical Oncology 2017;6: 189-192.

*Corresponding author:

Dr. Prashant Shivaji Mane, Kolhapur Cancer Centre, A/p. R. S. No. 238, Gokul Shirgaon, Karveer, Kolhapur, Maharashtra 416234 INDIA

Phone: +91 9359594677

Email: prashantmane0791@gmail.com

Financial or other Competing Interests: None. 